\title{
Pobreza multidimensional nos municípios da Região Nordeste
}

\author{
Janaina Ottonelli \\ Universidade Federal de Santa Maria \\ Jorge Luiz Mariano \\ Universidade Federal do Rio Grande do Norte
}

\begin{abstract}
Na abordagem das capacitações de Sen $(1981,1985,2000,2001)$, a pobreza significa privação em diferentes aspectos da vida. O objetivo deste estudo é mensurar a pobreza multidimensional nos municípios da Região Nordeste por meio da teoria dos conjuntos fuzzy e dados do Censo Demográfico (IBGE, 2010). São utilizados 19 indicadores (funcionamentos) distribuídos em quatro dimensões: educação, saúde, condições habitacionais e renda. Os resultados indicam pobreza, com destaque nas dimensões da renda e da educação, principalmente nos estados de Maranhão, Alagoas, Piauí e Paraíba. Políticas de redução da pobreza precisam considerar quais são as privações sofridas pelas pessoas e as particularidades do local onde vivem.
\end{abstract}

Palavras-chave: pobreza; abordagem das capacitações; teoria dos conjuntos fuzzy; Região Nordeste.

Pobreza multidimensional en las ciudades de la Región Nordeste

En el enfoque de las capacidades de Sen (1981, 1985, 2000, 2001), la pobreza es la privación en diferentes aspectos de la vida. El objetivo de este estudio es medir la pobreza multidimensional en las ciudades del Región Noroeste a través de la teoría de conjuntos fuzzy y Censo Demográfico (IBGE, 2010). Se utilizan 19 indicadores (funcionamientos) distribuidas en cuatro áreas: educación, salud, condiciones de vivienda e ingresos. Los resultados indican la pobreza, destacando las dimensiones de los ingresos y la educación, especialmente en los estados de Maranhão, Alagoas, Piauí y Paraíba. Políticas de reducción de la pobreza deben tener en cuenta cuáles son las dificultades sufridas por el pueblo y las particularidades del lugar donde viven.

Palabras clave: pobreza; enfoque de las capacidades; teoría de conjuntos fuzzy; Región Nordeste.

Multidimensional poverty in the cities of the Northeast Region in Brazil

In Sen's capability approach $(1981,1985,2000,2001)$, poverty means deprivation in different aspects of life. The aim of this study is to measure the multidimensional poverty in the counties of Northeast

DOI: http://dx.doi.org/10.1590/0034-76121724

Artigo recebido em 12 set. 2013 e aceito em 8 maio 2014.

Rev. Adm. Pública - Rio de Janeiro 48(5):1253-1279, set./out. 2014 
Region through the fuzzy set theory and Demographic Census data (IBGE, 2010). There were 19 indicators (functioning) divided into four dimensions: education, health, housing conditions and income. The results indicate poverty, highlighting the dimensions of income and education, particularly in the states of Maranhão, Alagoas, Piauí and Paraíba. Poverty reduction policies need to consider what are the deprivations suffered by people and the particularities of the place where they live.

KEYWORDs: poverty; capability approach; fuzzy set theory; Northeast Region; Brazil.

\section{Introdução}

O Plano Brasil Sem Miséria (Brasil, 2011a, 2011b) apontou que mais de 16 milhões de pessoas eram extremamente pobres no país em 2010. Desse total, 59\% estavam na Região Nordeste, 9,6 milhões. O governo federal define como extrema pobreza a situação em que os indivíduos possuem renda abaixo da renda familiar per capita mensal de até $\mathrm{R} \$ 70,00$, considerada uma linha da pobreza que separa os pobres dos não pobres. Nessa definição, a pobreza é observada apenas do ponto de vista monetário.

Apesar de o nível de renda ser uma dimensão importante da pobreza, é um indicador que não captura completamente outras privações sofridas pelas pessoas. Nesse sentido, Sen $(1985,1999,2000,2001)$ oferece uma nova abordagem para o conceito da pobreza: a abordagem das capacitações. Afirma que ser pobre abrange múltiplos aspectos, quantitativos e qualitativos, que incluem insuficiência de renda, acesso a bens, educação, saúde, moradia e trabalho. Fornece um reconhecimento mais completo da variedade de maneiras pelas quais as vidas das pessoas podem ser enriquecidas e empobrecidas (Sen, 2001).

Desse modo, acredita-se que na Região Nordeste, mesmo com o maior número de pobres na dimensão renda, também exista pobreza em outras dimensões. O objetivo deste estudo é mensurar a pobreza multidimensional nos 1.794 municípios nordestinos. Para isso, construiu-se um índice da pobreza multidimensional a partir da teoria dos conjuntos fuzzy e dos dados publicados no Censo Demográfico (IBGE, 2010).

Por meio dessa metodologia, ainda pouco aplicada em estudos no Brasil, espera-se identificar em quais aspectos (funcionamentos) existe maior privação e quais municípios apresentam maior propensão à situação da pobreza. Desse modo, busca-se contribuir na geração de informações sobre quais aspectos merecem maior atenção por formuladores de políticas públicas para a redução da pobreza. Para isso, apresentam-se o conceito da pobreza multidimensional conforme a abordagem das capacitações, a metodologia que permitiu a mensuração da pobreza, os resultados encontrados para os municípios da Região Nordeste e as considerações finais. 


\section{Abordagem das capacitações: uma noção multidimensional da pobreza}

Para discutir a natureza da pobreza, Sen (2001) cita um exemplo que compara duas pessoas. A pessoa 1 tem nível de renda mais baixo. Mas a pessoa 2 tem problemas nos rins, precisa fazer tratamento de diálise que custa caro e ela também tem uma vida muito mais empobrecida do que 1. Então, questiona: qual das duas é mais pobre, a pessoa 1, devido a sua renda mais baixa, ou a pessoa 2, por seu "conjunto capacitário" (o tipo de vida que leva) mais limitado?

Conforme a abordagem das capacitações, pobreza significa privação. Não apenas a privação causada pela insuficiência de renda monetária, mas também a que impede as pessoas de levarem a vida que desejam. Isso pode significar a falta de acesso ao ensino, aos serviços de saúde e de saneamento básico, ao mercado de trabalho, a uma habitação decente e também à participação da vida da comunidade (Sen, 1981).

O crescimento econômico é importante para a superação da pobreza, pois com mais renda as pessoas podem adquirir alimentos, roupas, bens de que necessitam ou desejam, melhorar suas condições habitacionais, entre outras coisas (Sen, 2000). Mas, conforme Aristóteles (apud Sen, 2000:28), "a riqueza evidentemente não é o bem que estamos buscando, sendo ela meramente útil e em proveito de alguma outra coisa". Renda ou riqueza não são desejáveis por si mesmas, pois "o que podemos ou não fazer, podemos ou não realizar, não depende somente das nossas rendas, mas também da variedade de características físicas e sociais que afetam nossas vidas e fazem de nós o que somos" (Sen, 2001:60).

Sen (2000) identifica cinco fontes distintas de variações entre as rendas reais e as vantagens - o bem-estar e a liberdade - que delas são obtidas: i) heterogeneidades pessoais: idade, gênero, propensão a doenças, incapacidade; ii) diversidades ambientais: variações nas condições ambientais e circunstâncias climáticas (temperatura, níveis pluviométricos); iii) variações no clima social: condições sociais como oferta de serviços públicos de educação, saúde, saneamento básico, infraestrutura, presença de violência; iv) diferenças de perspectivas relativas: necessidades de mercadorias em dada sociedade podem variar entre comunidades conforme convenções e costumes; v) distribuição na família: em cada família as rendas auferidas são compartilhadas por todos os membros, nem sempre de forma igual.

A abordagem das capacitações considera, portanto, a pobreza como a privação para alcançar certos funcionamentos minimamente aceitáveis (Sen, 1981, 1985, 1999, 2000, 2001). Os funcionamentos compreendem os seres e fazeres (beings and doings) e podem variar de elementares como estar bem nutrido, adequadamente vestido e abrigado, livre de doenças evitáveis, até realizações sociais mais complexas como ser feliz, ter respeito próprio e participar da vida da comunidade (Sen, 2001). A capacitação é a "liberdade substantiva de realizar combinações alternativas de funcionamentos (ou a liberdade para ter estilos de vida diversos)" (Sen, 2000:95).

A liberdade pode ser considerada o fim primordial e o principal meio do desenvolvimento humano (Sen, 2000, 2001). A liberdade como o fim primordial, ou o papel constitutivo, relaciona-se à importância da liberdade substantiva no enriquecimento da vida humana. Tende a contribuir para a capacitação geral de uma pessoa viver livremente. A liberdade como 
o principal meio, ou papel instrumental, refere-se ao modo como diferentes tipos de direitos, oportunidades e intitulamentos contribuem para a expansão da liberdade humana em geral. São: i) liberdades políticas (e direitos civis); ii) facilidades econômicas; iii) oportunidades sociais; iv) garantias de transparência; v) segurança protetora.

Com mais liberdade, as pessoas podem desfrutar de um maior número de funcionamentos relevantes, expandir seu conjunto capacitário e exercer o papel de agente. Para Sen (2000:33), agente é aquele que age e ocasiona mudança, aquele que assume o papel "como membro do público e como participante das ações econômicas, sociais e políticas".

Portanto, o exemplo comparativo entre a pessoa 1 e a pessoa 2 mostra que a pobreza não está apenas na privação de renda de 1. É mais evidente no conjunto de privação de renda e de saúde sofrida por 2, que tem mais dificuldade de agir para melhorar sua situação. Desse modo, o conceito da pobreza defendido pela abordagem das capacitações melhora o entendimento da natureza e das causas da pobreza e da privação, desviando a atenção dos meios (renda monetária) para os fins que as pessoas têm razão para buscar e para as liberdades de poder alcançar esses fins.

\section{Aspectos metodológicos}

\subsection{Operacionalização da abordagem das capacitações via teoria dos conjuntos fuzzy}

A abordagem das capacitações de Sen (2000) permite a avaliação da pobreza uma vez que os funcionamentos individuais podem ser usados para comparações individuais. Desse modo, a perspectiva da capacitação pode ser considerada pluralista por três motivos. Primeiro, porque existem funcionamentos diferentes e alguns podem ser mais importantes do que outros. Segundo, existe a questão sobre qual peso atribuir à liberdade substantiva (conjunto capacitário) em confronto com a realização real (vetor de funcionamentos escolhido). E, terceiro, existe a questão relacionada com a qual peso deve ser atribuído às capacitações.

Comim (2001) sugere que a abordagem de Sen pode ser operacionalizada de diferentes maneiras. Classifica os principais usos empíricos em cinco grupos: (i) estudos multivariados: para identificar e medir os funcionamentos (análise de compontentes principais, análise fatorial, teoria dos conjuntos fuzzy); (ii) estudos empíricos: técnicas econométricas e estatística descritiva da pobreza dada por indicadores monetários (construção de índices); (iii) estudos de caso: dados descritivos para contextualizar a complexidade de certa situação, como cuidados com a saúde (pesquisas domiciliares); (iv) aplicação teórica: para compreender a análise de situações de interesse; (v) aplicação metodológica: para discutir questões que são difícies de serem compreendidas via a abordagem utilitarista. Afirma que a escolha da estratégia depende do contexto e da proposta de aplicação da abordagem das capacitações.

Desse modo, neste estudo aplica-se a teoria dos conjuntos fuzzy (fuzzy sets theory) desenvolvida por Zadeh (1965) para a investigação da pobreza multidimensional por apresentar 
algumas vantagens. Possui um âmbito de aplicação muito amplo, pois oferece uma maneira para formalizar problemas que envolvem imprecisões. Tem sido aplicada em muitas áreas do conhecimento, como matemática, biologia e engenharia. Recentemente, tem sido usada para a análise do bem-estar, pobreza, desenvolvimento humano e desigualdade. Em alguns trabalhos esteve associada à abordagem das capacitações, como em Chiappero-Martinetti (2000), Lelli (2001) e Baliamoune-Lutz (2004).

Brevemente, Chiappero-Martinetti (2000) explica que a teoria dos conjuntos fuzzy substitui a função característica de um conjunto nítido ou clássico (crisp set) que tradicionalmente indica um valor de 1 ou 0 para cada elemento no conjunto universo, com uma função característica generalizada (chamada função membro) que varia entre 0 e 1 . Valores maiores denotam graus mais elevados de associação.

Em termos formais, se $X$ denota um conjunto universal, então a função membro:

$$
\mu_{A}: X \rightarrow[0,1]
$$

Em que: [0,1] é o intervalo de números reais de 0 a 1 . Portanto $\mu_{A}(X)=0$ se $x \in X$ não pertence a $A, \mu_{A}(X)=1$ se $x$ pertence completamente a $A$, e $0<\mu_{A}(X)=1$ se $x$ pertence parcialmente a $A$.

Chiappero-Martinetti (2000) assume que o subconjunto $A$ define a posição de cada indivíduo de acordo com o grau de associação. Nesse caso, valores membros iguais a 1 identificam uma condição de associação completa com respeito a um dado funcionamento, enquanto um valor igual a 0 denota a situação oposta de não associação total. Quando se consideram variáveis quantitativas e variáveis qualitativas mensuradas em uma escala ordinal, valores intermediários entre 0 e 1 descrevem posições graduais dentro do arranjo.

Com relação ao cálculo do índice fuzzy da pobreza, Pacheco, Del-Vecchio e Kerstenetzky (2010) afirmam poder existir duas situações. Em uma, as variáveis têm relação positiva com a pobreza, ou seja, quando o valor da variável aumenta, a pobreza aumenta (ex.: percentual de analfabetos). Utiliza-se a seguinte fórmula para definir a função de associação, o índice inicial para cada indicador considerado:

$$
x_{i j}=\frac{N_{j}-\operatorname{Min}_{j}}{\operatorname{Max}_{j}-\operatorname{Min}_{j}}
$$

Em que: $x_{i j}$ é o valor do índice fuzzy para o indicador j calculado para o município i; $N_{j}$ é o valor observado da série do indicador j para o município i; Min é o valor mínimo da série do indicador j; $\operatorname{Max}_{j}$ é o valor máximo da série do indicador j.

A outra situação envolve as variáveis de relação negativa com a pobreza, ou seja, quando o valor da variável aumenta, reduz-se a pobreza (ex.: acesso a energia elétrica). Utiliza-se a seguinte fórmula: 


$$
x_{i j}=\frac{\operatorname{Max}_{j}-N_{j}}{\operatorname{Max}_{j}-\operatorname{Min}_{j}}
$$

O estabelecimento desses limites máximos e mínimos dependerá da variável em análise. Depois de definida a função de associação, encontra-se a média aritmética das observações de cada variável, formando-se um indicador fuzzy elementar. Desse modo, o índice fuzzy obtido é relativo, pois o índice de um município com relação a um determinado indicador depende dos valores dos outros municípios em relação ao mesmo indicador.

A partir do índice relativo é preciso agregar esses indicadores. Chiappero-Martinetti (2000) explica que um subconjunto de indicadores elementares permite que se obtenha um índice sintético para cada funcionamento realizado. Já o conjunto de todos os funcionamentos realizados forma uma medida total de bem-estar. Segundo Pacheco, Del-Vecchio e Kerstenetzky (2010), para agregar os indicadores elementares deve-se estabelecer um determinado peso para cada variável. A escolha dos pesos pode ser feita com base em um instrumental matemático. A vantagem dessa metodologia é que não haveria arbitrariedade nessa escolha. Desse modo, os pesos dos indicadores são calculados, ponderados pelo tamanho da população no município, com base na seguinte equação proposta por Diniz e Diniz (2009):

$$
w_{j}=\ln \left[n /\left(n-\sum_{i=1}^{n} x_{i j}\right)\right] \geq 0
$$

Em que: $w_{j}$ é o peso do indicador $\mathrm{j} ; x_{i j}$ é o valor do índice fuzzy para o indicador $\mathrm{j}$ calculado para o município $i$; $n$ é o número total de municípios em cada estado.

Conforme Pacheco, Del-Vecchio e Kerstenetzky (2010), um indicador que apresenta altos índices para a maioria dos municípios terá um peso menor do que um indicador que apresentou índices menores em muitos municípios, isto é, fixando j, quanto maior forem os $x_{i j}$ (maior denominador), menor será $w_{j}$. Isso traduz a intenção de dar maior peso a um atributo no qual a maioria dos agentes investigados apresenta um grau da pobreza relevante, portanto a privação em relação a ele será mais destacada do que a privação referente a um atributo que está disponível para a maioria.

A agregação do índice fuzzy da pobreza multidimensional (IFP) em dimensões e no índice global, conforme o peso de cada variável, é feita conforme:

$$
\mu_{i}=\sum_{j=1}^{n} x_{i j} w_{j} / \sum_{j=1}^{n} w_{j}
$$

Em que: $\mu_{i}$ é o índice fuzzy multidimensional agregado do município $\mathrm{i} ; x_{i j}$ é o valor do índice fuzzy para o indicador j calculado para o município i e $w_{j}$ é o peso do indicador $\mathrm{j}$. 
Em resumo, o cálculo dos índices fuzzy da pobreza multidimensional (IFP) para cada município considerado neste estudo envolve alguns passos. O primeiro é calcular um índice fuzzy $x_{i j}$ relativo a todos os municípios da Região Nordeste para cada indicador, observando a relação positiva ou negativa com a pobreza. O segundo é calcular pesos para índices $x_{i j}$ e então agregá-los nas dimensões. O terceiro é calcular os pesos para cada dimensão para verificar qual possui maior impacto no índice global. Em seguida, agregam-se os índices das dimensões obtendo-se o índice fuzzy da pobreza multidimensional para cada município, o IFP.

Os conjuntos fuzzy consistem em uma forma de quantificação de situações imprecisas, como na análise da pobreza, em que os valores fuzzy revelariam distintos graus da pobreza. Esta análise normalmente não utiliza linhas da pobreza. O valor fuzzy da pobreza pode ser interpretado como uma expressão do grau de vulnerabilidade da unidade analisada (indivíduo, família, domicílio, unidade geográfica) à situação da pobreza, vulnerabilidade não no sentido de probabilidade, mas no sentido de proximidade da situação da pobreza. Assim, um indivíduo com um valor fuzzy da pobreza de 0,9 está mais próximo da pobreza do que outro com um valor de 0,4 - e é apenas nesse sentido que o risco de ele ser indubitavelmente pobre é maior do que o do segundo indivíduo (Pacheco, Del-Vecchio e Kerstenetzky, 2010).

A abordagem fuzzy da pobreza indica, em combinação com a abordagem multidimensional, em que dimensão o indivíduo é especialmente pobre (Carvalho, Kerstenetzky e DelVecchio, 2007). Essa informação é especialmente importante para os formuladores de políticas públicas, dado que uma política de combate à pobreza será mais efetiva se atender às dimensões corretas.

\subsection{Definição de dimensões e indicadores para medir a pobreza multidimensional}

Para Alkire (2002), a necessidade de especificar dimensões para o estudo da pobreza surge de diversas razões. A primeira ocorre em função do objetivo multidimensional, pois a pobreza precisa ser reduzida e o bem-estar precisa ser melhorado em diferentes aspectos. A segunda razão é prática e relaciona-se com a necessidade de metodologias efetivas para avaliar os tradeoffs. A terceira é que um conjunto de dimensões pode ajudar grupos a identificar impactos não intencionais. A razão final diz respeito à determinação de dimensões que sejam facilmente entendidas, pois teorias que não são de uso "amigável" não se espalham.

Existe um grande número de pesquisadores que escolhem dimensões para analisar a pobreza multidimensional, mas que não explicam suas razões pelas escolhas (Alkire, 2008). Dessa forma, o leitor é incapaz de sondar as dimensões escolhidas, confiar nelas ou questioná-las. Portanto, as dimensões são escolhidas por conveniência, com base nos valores das pessoas ou por convenção dentro da literatura. Robeyns (apud Alkire, 2008) sugere que é de grande valor quando os autores descrevem explicitamente como e por que eles escolheram as dimensões.

As dimensões, quando pensadas para avaliar a privação das capacitações, não devem formar uma lista fixa. A abordagem das capacitações deve ser aplicada de forma diferente 
dependendo do local e da situação, o nível de análise, a informação disponível e o tipo de decisão. O método deve ser plural e as técnicas empregadas devem considerar cada contexto. O que a perspectiva da capacitação oferece é um quadro em relação ao qual a investigação da pobreza multidimensional e várias questões de política podem ser analisadas e as múltiplas privações que muitos sofrem podem ser reduzidas (Alkire, 2008).

Alkire (2008) salienta que para Sen as capacitações-chave devem ser selecionadas, mas não deve existir a especificação de uma única lista de capacitações a ser aplicada em todos os momentos e lugares. A posição de Sen deixa pesquisadores sem qualquer orientação sistemática de como escolher as capacitações ou domínios em diferentes contextos.

No entanto, apesar de a seleção das dimensões ser complexa, Alkire (2008) identifica cinco processos pelos quais isso pode ser feito: (1) usar os dados existentes; (2) fazer suposições, talvez com base em uma teoria; (3) selecionar uma lista de dimensões que atingiu um grau de legitimidade, como resultado de consenso público; (4) usar um processo constante de participação deliberativa; (5) propor dimensões com base em estudos empíricos sobre os valores das pessoas e/ou comportamentos.

A definição das dimensões deste estudo segue tais processos. Primeiro, para verificar a propensão à situação da pobreza multidimensional são usados dados do Censo Demográfio 2010 (IBGE, 2010) para os 1.794 municípios pertencentes aos nove estados da Região Nordeste: Alagoas, Bahia, Ceará, Maranhão, Paraíba, Pernambuco, Piauí, Rio Grande do Norte e Sergipe. Segundo, a investigação tem como base a abordagem das capacitações de Sen, teoria que considera a pobreza um problema multidimensional.

No terceiro e quarto processos, foram pesquisados listas de dimensões e indicadores propostos em alguns estudos. O índice de desenvolvimento humano (IDH) apresenta uma metodologia multidimensional de análise. Mede as realizações de um país em três dimensões básicas do desenvolvimento humano: "vida longa e saudável", medida pelo indicador esperança de vida ao nascer; "acesso ao conhecimento", medida pela média dos indicadores anos de escolaridade e anos de escolaridade esperados; e "padrão de vida digno", medida pelo indicador rendimento nacional bruto per capita (Pnud, 2010; 2011).

No Brasil, estudos que investigam a pobreza multidimensional baseados na teoria de Sen são os de Bagolin e Ávila (2006), Marin e Ottonelli (2008), Ottonelli e colaboradores (2011) e Marin e colaboradores (2013). Alguns estudos nacionais e internacionais investigam a pobreza por meio do cálculo dos índices fuzzy. Chiappero-Martinetti (2000) definiu o espaço dos funcionamentos em cinco indicadores elementares para dados da Itália de 1994: domicílio, saúde, educação e conhecimento, interações sociais e condições psicológicas. Como resultados, observam um grau elevado de realização nas dimensões materiais e de saúde e baixa realização nas dimensões de educação e conhecimento, bem como na participação social fora de família e amigos.

Brandolini e D’Alessio (1998) utilizaram seis categorias para representar funcionamentos das famílias italianas em 1995: saúde, educação, emprego, domicílio, relação social e recursos econômicos. Observam que a privação ocorre mais frequentemente em recursos econômicos, domicílio e saúde do que nas outras dimensões. 
Lelli (2001) utilizou os seguintes funcionamentos para os residentes na Bélgica em 1998: relações sociais, estado econômico, saúde, estado psicológico, atividades culturais e abrigo (domicílio). Aponta uma realização nas dimensões materiais (domicílio, condições econômicas e de trabalho), bem como de saúde e estado psicológico, em contraste com realizações pobres em relação às interações sociais e atividades culturais.

Picolotto (2006) aplica a técnica dos conjuntos fuzzy para avaliar funcionamentos entre uma amostra de 610 pessoas mais pobres vivendo na Região Metropolitana de Porto Alegre. Trata-se de um estudo com dados primários e está centrado nos seguintes funcionamentos realizados: saúde, nutrição, educação, participação, solidariedade, liberdade e satisfação. Os piores resultados em realização, que indicam maior pobreza, foram nos funcionamentos participação e educação.

Carvalho, Kerstenetzky e Del-Vecchio (2007) estudaram a pobreza nas regiões metropolitanas do Sudeste brasileiro em 2000. Escolheram 16 indicadores que representassem aspectos da situação socioeconômica dos indivíduos e os agruparam em quatro dimensões: educação, renda, saneamento básico e condições domiciliares, e população e saúde. Atribuíram pesos aos indicadores utilizando uma metodologia de escala de prioridades em que os indicadores que se encontram nos primeiros níveis recebem os maiores pesos e os que se encontram nos últimos níveis recebem os menores pesos. As principais causas da pobreza encontradas foram: abastecimento de água e banheiro em domicílios, abastecimento de energia elétrica e de esgoto, mortalidade infantil, probabilidade de não sobrevivência até os 40 anos de idade e o hiato da renda.

Pacheco, Del-Vechio e Kerstenetzky (2010), no estudo para bairros da Zona Oeste do Rio de Janeiro para 1991 e 2000, usaram 22 indicadores agrupados em: saúde, renda, educação e condições domiciliares. Confome os autores, os altos valores encontrados para o ano 2000 se devem principalmente aos problemas do escasso acesso relativo a serviços públicos como água encanada, esgotamento sanitário e energia elétrica, taxa de fecundidade, realizações educacionais deficientes, sobretudo de crianças e adolescentes fora da escola.

Diniz e Diniz (2009) investigaram a situação da pobreza nos estados brasileiros. Usaram 12 indicadores para representar as sete metas dos Objetivos do Desenvolvimento do Milênio: erradicar a extrema pobreza e a fome; atingir o ensino básico universal; promover a igualdade entre os sexos e a autonomia das mulheres; reduzir a mortalidade infantil; melhorar a saúde materna; combater o HIV/Aids, a malária e outras doenças; garantir a sustentabilidade ambiental. Os indicadores e os que apresentaram maior peso no índice foram: defasagem escolar, mortalidade infantil, mortalidade materna, incidência de HIV/Aids, falta de acesso a água e a esgotamento sanitário (este obteve o maior peso dentre os indicadores).

Para atingir o quinto e último processo proposto por Alkire (2008), definiram-se os indicadores e dimensões considerados no cálculo do índice fuzzy da pobreza multidimensional (IFP) para os municípios da Região Nordeste. Foram escolhidos 19 indicadores distribuídos em quatro dimensões: educação, saúde, condições habitacionais e renda (quadro 1). Com 
essas dimensões busca-se captar as múltiplas facetas do problema da pobreza, que englobam aspectos sociais, ambientais e econômicos característicos de determinado local.

Quadro 1

Lista de dimensões e indicadores escolhidos para cálculo do IFP

\begin{tabular}{|c|c|}
\hline Dimensões & Indicadores \\
\hline 1. Educação & $\begin{array}{l}\text { 1.1 Taxa de alfabetização de pessoas de } 5 \text { anos ou mais } \\
\text { 1.2 Percentual de pessoas de } 5 \text { a } 14 \text { anos não alfabetizadas } \\
\text { 1.3 Percentual de pessoas de } 15 \text { anos ou mais não alfabetizadas } \\
\text { 1.4 Percentual de domicílios em que a pessoa responsável não é alfabetizada } \\
\text { 1.5 Percentual de pessoas de } 10 \text { anos ou mais segundo o nível de instrução: sem instrução } \\
\text { e ensino fundamental incompleto } \\
\text { 1.6 Percentual de pessoas de } 10 \text { anos ou mais segundo o nível de instrução: fundamental } \\
\text { completo e ensino médio incompleto } \\
\text { 1.7 Percentual de pessoas de } 10 \text { anos ou mais segundo o nível de instrução: ensino médio } \\
\text { completo e superior incompleto }\end{array}$ \\
\hline 2. Saúde & $\begin{array}{l}\text { 2.1 Mortalidade infantil (até } 1 \text { ano de idade) } \\
\text { 2.2 Mortalidade até } 5 \text { anos de idade } \\
\text { 2.3 Percentual de crianças e adolescentes, de } 10 \text { a } 17 \text { anos, com filhos } \\
\text { 2.4 Percentual de domicílios com acesso aos tipos de esgotamento sanitário: rede geral de } \\
\text { esgoto ou pluvial ou fossa séptica }\end{array}$ \\
\hline 3. Condições Habitacionais & $\begin{array}{l}\text { 3.1 Percentual de domicílios com acesso a energia elétrica } \\
\text { 3.2 Percentual de domicílios com acesso a rede de água } \\
\text { 3.3 Percentual de domicílios com acesso a coleta de lixo } \\
\text { 3.4 Percentual de domicílios com banheiro } \\
\text { 3.5 Percentual de domicílios com densidade de moradores por dormitório acima de dois } \\
\text { moradores } \\
\text { 3.6 Percentual de domicílios com acesso ao bem durável geladeira }\end{array}$ \\
\hline 4. Renda & $\begin{array}{l}\text { 4.1 Valor do rendimento nominal médio mensal dos domicílios } \\
\text { 4.2 Percentual de domicílios com rendimento de até meio salário mínimo }\end{array}$ \\
\hline
\end{tabular}

Fonte: Elaborado pelos autores.

A dimensão educação é medida por sete indicadores para capturar informações sobre o nível de alfabetização geral e o acesso aos ensinos básico e superior. A dimensão saúde investiga o acesso ao serviço de saneamento básico, mortalidade infantil e gravidez precoce. A dimensão condições habitacionais verifica as condições mínimas de habitação dos domicílios. Por fim, a dimensão renda verifica o valor do rendimento mensal domiciliar e também o acesso dos domicílios a, pelo menos, meio salário mínimo.

\section{0 índice fuzzy da pobreza multidimensional (IFP) para os municípios da Região Nordeste}

A definição de indicadores e dimensões permitiu o cálculo do índice fuzzy da pobreza multidimensional (IFP) para os 1.794 municípios da Região Nordeste em 2010. Os pesos mostrados 
no quadro 2 indicam quais indicadores e dimensões apresentam maior impacto sobre a pobreza. Observa-se que a dimensão renda apresentou maior peso (1.38), o que já era esperado. Na sequência, os maiores valores são das dimensões educação $(1,04)$, saúde $(0,86)$ e condições habitacionais $(0,36)$. Tais informações são discutidas com mais detalhes juntamente com a apresentação dos resultados do IFP de cada dimensão.

Quadro 2

Lista de pesos por indicador e dimensão usados no cálculo do IFP

\begin{tabular}{|c|c|c|c|}
\hline Dimensão & Indicador & $\begin{array}{l}\text { Ponderação } \\
\text { por indicador }\end{array}$ & $\begin{array}{l}\text { Ponderação } \\
\text { por dimensão }\end{array}$ \\
\hline \multirow[t]{7}{*}{ Educação } & 1.1 Taxa de alfabetização de pessoas de 5 anos ou mais & 0,771 & \multirow{7}{*}{1,044} \\
\hline & 1.2 Percentual de pessoas de 5 a 14 anos não alfabetizadas & 0,305 & \\
\hline & 1.3 Percentual de pessoas de 15 anos ou mais não alfabetizadas & 0,776 & \\
\hline & $\begin{array}{l}\text { 1.4 Percentual de domicílios em que a pessoa responsável não é } \\
\text { alfabetizada }\end{array}$ & 0,869 & \\
\hline & $\begin{array}{l}1.5 \text { Percentual de pessoas de } 10 \text { anos ou mais segundo o nível de } \\
\text { instrução: sem instrução e ensino fundamental incompleto }\end{array}$ & 1,229 & \\
\hline & $\begin{array}{l}\text { 1.6 Percentual de pessoas de } 10 \text { anos ou mais segundo o nível de } \\
\text { instrução: fundamental completo e ensino médio incompleto }\end{array}$ & 1,408 & \\
\hline & $\begin{array}{l}1.7 \text { Percentual de pessoas de } 10 \text { anos ou mais segundo o nível de } \\
\text { instrução: ensino médio completo e superior incompleto }\end{array}$ & 1,340 & \\
\hline \multirow[t]{4}{*}{ Saúde } & 2.1 Mortalidade infantil (até 1 ano de idade) & 0,124 & \multirow{4}{*}{0,860} \\
\hline & 2.2 Mortalidade até 5 anos de idade & 0,139 & \\
\hline & 2.3 Percentual de crianças e adolescentes, de 10 a 17 anos, com filhos & 0,243 & \\
\hline & $\begin{array}{l}\text { 2.4 Percentual de domićlios com acesso aos tipos de esgotamento } \\
\text { sanitário: rede geral de esgoto ou pluvial ou fossa séptica }\end{array}$ & 1,322 & \\
\hline \multirow{6}{*}{$\begin{array}{l}\text { Condições } \\
\text { Habitacionais }\end{array}$} & 3.1 Percentual de domicílios com acesso a energia elétrica & 0,084 & \multirow{6}{*}{0,395} \\
\hline & 3.2 Percentual de domicílios com acesso a rede de água & 0,425 & \\
\hline & 3.3 Percentual de domicílios com acesso a coleta de lixo & 0,551 & \\
\hline & 3.4 Percentual de domicílios com banheiro & 0,355 & \\
\hline & $\begin{array}{l}\text { 3.5 Percentual de domicílios com densidade de moradores por } \\
\text { dormitório acima de } 2 \text { moradores }\end{array}$ & 0,329 & \\
\hline & 3.6 Percentual de domicílios com acesso ao bem durável geladeira & 0,322 & \\
\hline \multirow[t]{2}{*}{ Renda } & 4.1 Valor do rendimento nominal médio mensal dos domicílios & 1,809 & \multirow{2}{*}{1,380} \\
\hline & 4.2 Percentual de domicílios com rendimento de até meio salário mínimo & 0,799 & \\
\hline
\end{tabular}

Fonte: Elaborado com os resultados do cálculo dos IFP.

Os resultados encontrados para o IFP são apresentados em figuras e tabelas por meio de quatro intervalos de classes, que variam conforme a informação ilustrada. Os valores mais baixos do índice indicam menor propensão à situação da pobreza (cor mais clara). Os valores mais altos dos índices indicam maior propensão à pobreza (cor mais escura). 


\subsection{IFP educação}

Os resultados do IFP para a dimensão educação (fig. 1) mostram que municípios com maior propensão à situação da pobreza, identificados pela cor mais escura, estão localizados principalmente nos estados do Maranhão, Piauí, Pernambuco, Alagoas e Sergipe. E os municípios com menor propensão à pobreza, identificados pela cor mais clara, localizam-se principalmente no Ceará, Rio Grande do Norte e Bahia.

\section{Figura 1}

Índice fuzzy da pobreza para a dimensão educação

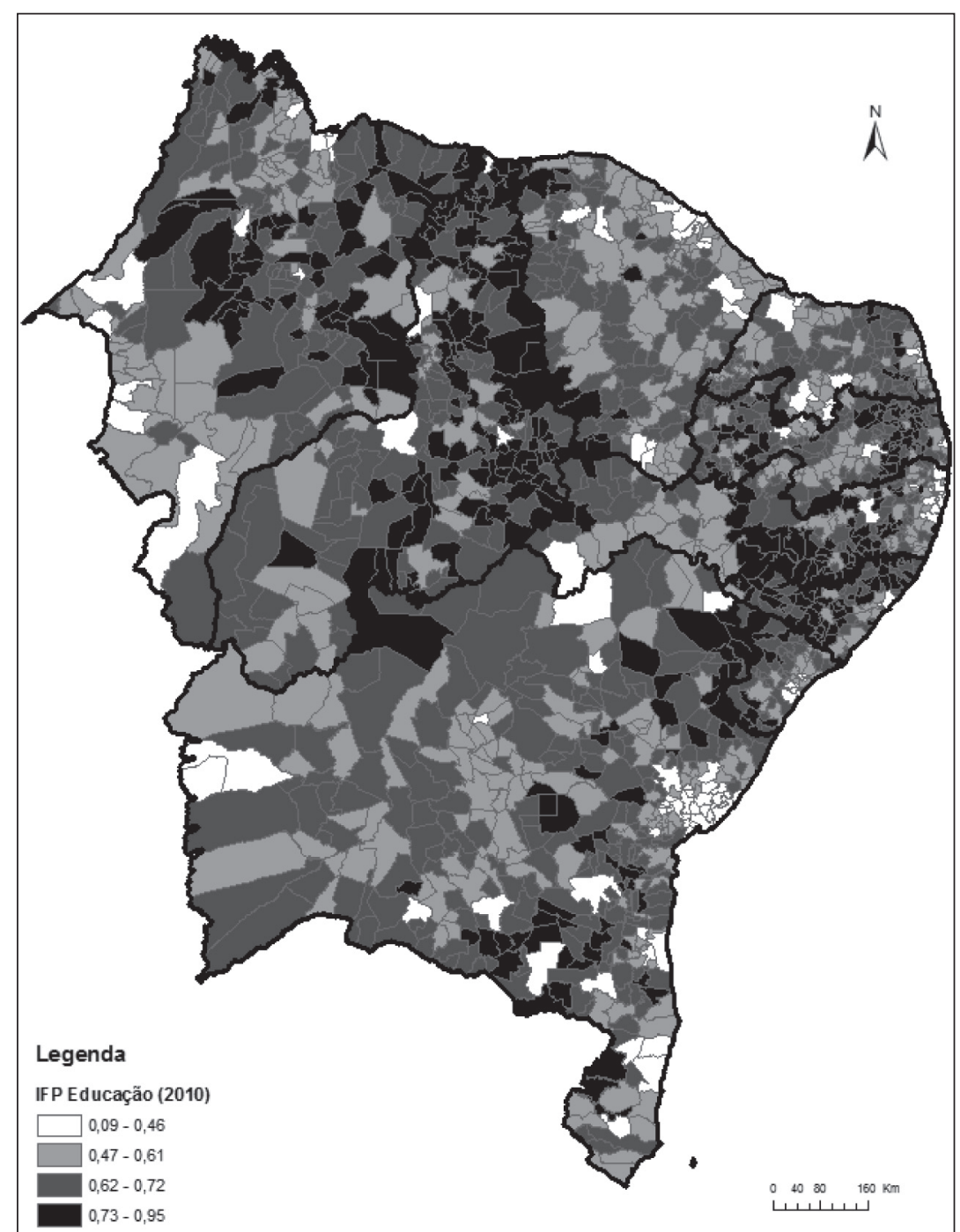

Fonte: Elaborada com dados do IBGE - Censo Demográfico 2010. 
A tabela 1 mostra a distribuição dos municípios conforme o intervalo de classe do IFP educação. Na classe que indica maior propensão à pobreza, com valores próximos a 1 , destacam-se os municípios de Alagoas (57,8\%), Piauí (47\%), Paraíba (36,8\%), Pernambuco $(28,6 \%)$ e Maranhão (23\%). Na classe que indica menor propensão à pobreza, valores próximos a 0, destacam-se os da Bahia (10,8\%), Sergipe (10,7\%), Ceará (8,7\%) e Pernambuco (8\%). Verifica-se que a maioria dos municípios, mais de 65\%, apresenta índice de educação nas classes que indicam maior propensão à pobreza, acima de 0,62.

Tabela 1

Municípios por intervalo de classes do IFP educação

\begin{tabular}{|cccccc|}
\hline \multicolumn{5}{c|}{ IFP Educação } \\
\hline \multirow{2}{*}{ Estado } & $\begin{array}{c}\text { Número de } \\
\text { municípios }\end{array}$ & \multicolumn{4}{c|}{ Percentual de municípios por intervalo de classes (\%) } \\
\cline { 3 - 6 } & 102 & $0,09-0,46$ & $0,47-0,61$ & $0,62-0,72$ & $0,73-0,95$ \\
\hline Alagoas & 1,96 & 9,80 & 30,39 & 57,84 \\
Bahia & 417 & 10,79 & 29,50 & 46,52 & 13,19 \\
Ceará & 184 & 8,70 & 45,65 & 39,13 & 6,52 \\
Maranhão & 217 & 5,99 & 29,49 & 41,01 & 23,50 \\
Paraíba & 223 & 2,69 & 17,04 & 43,50 & 36,77 \\
Pernambuco & 185 & 8,11 & 29,73 & 33,51 & 28,65 \\
Piauí & 224 & 1,79 & 13,84 & 37,05 & 47,32 \\
Rio Grande do Norte & 167 & 5,99 & 32,93 & 49,70 & 11,38 \\
Sergipe & 75 & 10,67 & 26,67 & 45,33 & 17,33 \\
Total NE & 1794 & 6,63 & 26,76 & 41,53 & 25,08 \\
\hline
\end{tabular}

Fonte: Elaborada com dados do IBGE - Censo Demográfico 2010.

Conforme o quadro 2, a educação apresenta o segundo maior peso no índice, devido ao alto peso dos indicadores: percentual de pessoas com ensino fundamental completo e ensino médio incompleto $(1,40)$, percentual de pessoas com ensino médio completo e ensino superior incompleto $(1,34)$ e percentual de pessoas sem instrução e ensino fundamental incompleto $(1,22)$. Os outros indicadores que também tiveram impacto sobre o índice estão relacionados com a educação dos adultos: não alfabetização da pessoa responsável pelo domicílio $(0,86)$, percentual de pessoas de 15 anos ou mais não alfabetizadas $(0,77)$ e taxa de alfabetização de pessoas de cinco anos ou mais $(0,77)$. 
Nesse primeiro momento, chama a atenção o peso da dimensão educação, o que indica maior impacto sobre o índice da pobreza multidimensional investigado. Quando se analisam os pesos dos indicadores que a compõem, verifica-se o alto impacto da falta de acesso aos ensinos fundamental, médio e superior, da taxa de alfabetização e também da escolarização do responsável pelo domicílio. Isso denota a extrema importância da dimensão, conforme mostram os estudos de Chiappero-Martinetti (2000), Picolotto (2006), Pacheco, Del-Vechio e Kerstenetzky (2010) e Diniz e Diniz (2009).

Os resultados do IFP educação são preocupantes. Existe uma propensão à pobreza em um número muito elevado de municípios. Isso mostra que o acesso à educação precisa ser ampliado e melhorado, principalmente o acesso ao ensino fundamental e médio, indicadores que tiveram maior peso no índice. Os resultados também mostraram o impacto da falta de acesso à educação pela população adulta.

Conforme a abordagem das capacitações (Sen, 2000, 2001), pessoas com acesso a educação são capazes de exercer papéis na comunidade onde vivem, têm mais cuidado com sua saúde e dos seus familiares, conseguem decidir sobre o número de filhos que desejam ter, influenciam aos demais familiares sobre a importância da educação. A alfabetização do responsável pelo domicílio e dos adultos pode influenciar de maneira positiva sua vida e a dos demais membros, pois permite que seja agente de sua vida de forma a exercer direitos civis, participar da vida da comunidade e do mercado de trabalho.

\subsection{IFP saúde}

A figura 2 apresenta o IFP para a dimensão saúde. Observa-se maior propensão à situação da pobreza na dimensão saúde pelos municípios localizados principalmente na região oeste do Nordeste. Abrangem os municípios dos estados do Maranhão, Piauí, Bahia, Ceará e Alagoas. Com menor propensão, são os municípios de Pernambuco, parte do Rio Grande do Norte e Paraíba e sul da Bahia.

A tabela 2 mostra a distribuição dos municípios conforme o intervalo de classe do IFP saúde. Na classe que indica maior propensão à pobreza, acima de 0,66, destacam-se os municípios do Maranhão (73,7\%), Piauí (62\%), Alagoas (55,9\%), Bahia (41\%), Rio Grande do Norte $(40,7 \%)$ e Ceará $(40 \%)$. Na classe que indica menor propensão, valores menores que 0,33, os de Pernambuco (24,9\%) e Rio Grande do Norte (18,6\%). Verifica-se que a maioria dos municípios, quase $70 \%$, apresenta índice de saúde nas classes que indicam maior propensão a pobreza, acima de 0,51. 
Figura 2

Índice fuzzy da pobreza para a dimensão saúde

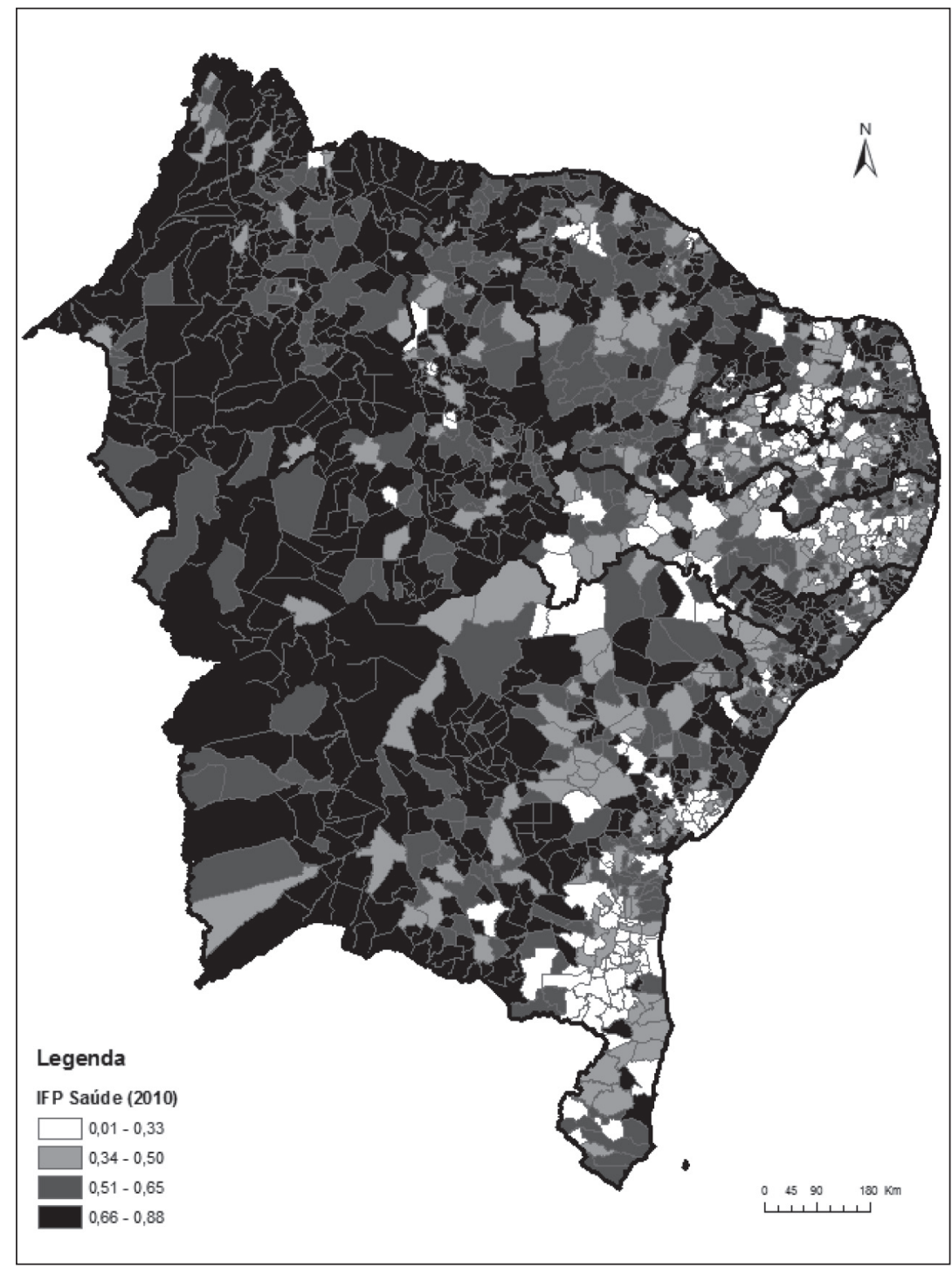

Fonte: Elaborada com dados do IBGE - Censo Demográfico 2010.

Conforme o quadro 2, o indicador que possui maior peso no índice da dimensão saúde é o relacionado com o esgotamento sanitário: o acesso à rede geral de esgoto ou fossa séptica $(1,32)$. Os demais indicadores, mortalidade até um ano de idade, mortalidade até cinco anos de idade e percentual de crianças e adolescentes com filhos, apresentam os respectivos pesos de $0,12,0,13$ e 0,24 . 
Tabela 2

Municípios por intervalo de classes do IFP saúde

\begin{tabular}{|cccccc|}
\hline \multirow{5}{*}{ Estado } & Número de & \multicolumn{4}{c|}{ Percentual de municípios por intervalo de classes (\%) } \\
\cline { 3 - 6 } & municípios & $0,01-0,33$ & $0,34-0,50$ & $0,51-0,65$ & $0,66-0,88$ \\
\hline Alagoas & 102 & 8,82 & 12,75 & 22,55 & 55,88 \\
Bahia & 417 & 16,55 & 17,99 & 24,46 & 41,01 \\
Ceará & 184 & 3,80 & 13,59 & 42,39 & 40,22 \\
Maranhão & 217 & 0,46 & 7,37 & 18,43 & 73,73 \\
Paraíba & 223 & 17,94 & 24,22 & 30,04 & 27,80 \\
Pernambuco & 185 & 24,86 & 42,16 & 27,03 & 5,95 \\
Piauí & 224 & 2,68 & 9,38 & 25,45 & 62,50 \\
Rio Grande do Norte & 167 & 18,56 & 13,17 & 27,54 & 40,72 \\
Sergipe & 75 & 12,00 & 28,00 & 21,33 & 38,67 \\
Total NE & 1794 & 12,15 & 18,12 & 26,70 & 43,03 \\
\hline
\end{tabular}

Fonte: Elaborada com dados do IBGE - Censo Demográfico 2010.

Os resultados mostram alta propensão à pobreza na dimensão saúde nos municípios nordestinos. A dimensão saúde é importante para que as pessoas levem uma vida de qualidade, livre de doenças evitáveis. A falta de destino adequado para o esgoto sanitário pode causar danos à saúde das pessoas. O indício de má saúde revela uma grave privação sofrida pelas pessoas, pois elas podem enfrentar dificuldades para tratamento médico e podem ficar incapazes de exercer suas funções no mercado de trabalho.

Destaca-se que o grande impacto no índice é causado pelo indicador de acesso ao serviço de esgotamento sanitário. Isso também é confirmado pelos trabalhos de Diniz e Diniz (2009), em que foi o indicador com maior peso, e também em Brandolini e D'Alessio (1998), Pacheco, Del-Vechio e Kerstenetzky (2010) e Carvalho, Kerstenetzky e Del-Vecchio (2007). O indicador de gravidez na infância e adolescência apresentou peso superior aos indicadores de mortalidade infantil.

Quanto mais cedo iniciarem os cuidados com a saúde, mais chances terão as crianças de reduzir o risco de morte, o risco de desenvolver doenças, de ter má formação, desnutrição. Por exemplo, um menor índice da pobreza pode ser alcançado com a oferta do serviço de atendimento de saúde à população carente, de forma que crianças, adultos e idosos tenham acompanhamento médico e acesso a remédios. Além disso, assegurar a limpeza pública, principalmente o destino correto do esgoto sanitário, deve ser reivindicado pela população e ser ofertado pelo serviço público. 


\subsection{IFP condições habitacionais}

A figura 3 apresenta o IFP para a dimensão das condições habitacionais. Observa-se que a maior propensão à pobreza foi encontrada principalmente nos municípios localizados no Maranhão e Piauí. Os municípios com menor propensão estão localizados nos estados do Rio Grande do Norte, Paraíba e Sergipe, Pernambuco, Alagoas e Bahia.

Figura 3

Índice fuzzy da pobreza para a dimensão condições habitacionais

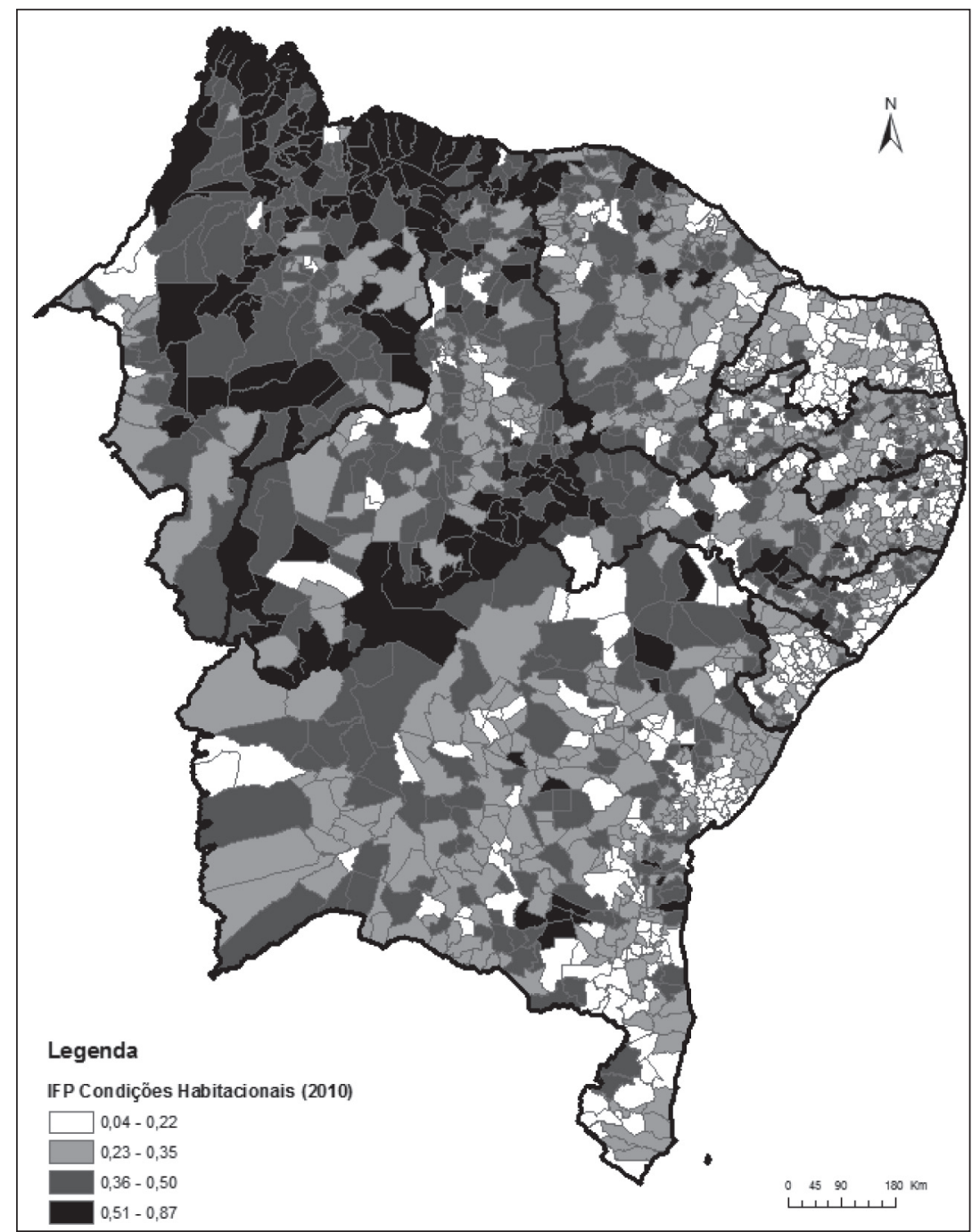

Fonte: Elaborada com dados do IBGE - Censo Demográfico 2010. 
A tabela 3 mostra a distribuição dos municípios por estado conforme o intervalo de classe do IFP condições habitacionais. Na classe que indica maior propensão à pobreza, acima de 0,51, destacam-se os municípios de Piauí (26,8\%), Maranhão (9,7\%) e Alagoas $(6,9 \%)$. Na classe que indica menor propensão, abaixo de 0,22, os municípios de Sergipe (60\%), Rio Grande do Norte $(58,7 \%)$ e Pernambuco (32\%). Verifica-se que a maioria dos municípios, mais de $66 \%$, apresenta índice nas classes que indicam menor propensão à pobreza, abaixo de 0,35.

Tabela 3

Municípios por intervalo de classes do IFP condições habitacionais

\begin{tabular}{|cccccc|}
\hline & \multicolumn{5}{c|}{ IFP Condições Habitacionais } \\
Estado & $\begin{array}{c}\text { Número de } \\
\text { municípios }\end{array}$ & \multicolumn{2}{c}{ Percentual de municípios por intervalo de classes (\%) } \\
Alagoas & 102 & $27,04-0,22$ & $0,23-0,35$ & $0,36-0,50$ & $0,51-0,87$ \\
Bahia & 417 & 26,38 & 29,41 & 36,27 & 6,86 \\
Ceará & 184 & 13,59 & 43,88 & 25,66 & 4,08 \\
Maranhão & 217 & 15,21 & 43,83 & 33,70 & 4,89 \\
Paraíba & 223 & 22,87 & 46,64 & 31,80 & 9,68 \\
Pernambuco & 185 & 32,43 & 40,00 & 26,46 & 4,04 \\
Piauí & 224 & 8,04 & 25,89 & 39,86 & 2,16 \\
Rio Grande do Norte & 167 & 58,68 & 37,13 & 4,19 & 26,79 \\
Sergipe & 75 & 60,00 & 33,33 & 6,67 & 0,00 \\
Total NE & 1794 & 26,09 & 40,02 & 26,76 & 7,08 \\
\hline
\end{tabular}

Fonte: Elaborada com dados do IBGE - Censo Demográfico 2010.

Os resultados encontrados mostram, para a maioria dos municípios, baixa propensão à situação da pobreza. Comparando-se os valores das classes entre as dimensões, observa-se que, para a dimensão condições habitacionais, os valores são menores entre as classes de menor propensão à pobreza. Isso indica um maior acesso dos municípios aos funcionamentos que compõem essa dimensão.

Conforme o quadro 2, os indicadores que possuem maiores pesos no índice da dimensão condições habitacionais são acesso à coleta de lixo $(0,55)$ e acesso à rede de água $(0,42)$. Os outros indicadores com grande participação no índice são existência de banheiro no domicílio $(0,35)$, densidade de moradores por dormitório $(0,32)$ e acesso ao bem durável geladeira 
$(0,32)$. O indicador de acesso à energia elétrica apresentou baixo peso no índice, o que mostra alto acesso a esse indicador pelos domicílios dos municípios.

Os indicadores da dimensão condições habitacionais apresentaram pesos baixos quando comparados com os demais. Os que se destacaram foram os de acesso à rede de água e à coleta de lixo no mesmo sentido de Diniz e Diniz (2009), Pacheco, Del-Vechio e Kerstenetzky (2010) e Carvalho, Kerstenetzky e Del-Vecchio (2007).

Verificou-se a menor privação sofrida pelas pessoas. Nessa dimensão, a maior privação foi encontrada nos indicadores relacionados com a coleta de lixo e acesso à rede de água. Em muitos municípios esses dois serviços ainda são precários. Destaca-se a importância do acesso à água potável e tratada para consumo; o destino adequado para o lixo de forma que não fique acumulado nas ruas próximas aos domicílios causando mau cheiro, poluição e proliferação de insetos e roedores causadores de doenças; o acesso à energia elétrica, que permite o acesso a bens duráveis, como a geladeira, que ajudam na conservação de alimentos; o acesso ao banheiro e a densidade de moradores por dormitório, que refletem a qualidade de vida.

\subsection{IFP renda}

A figura 4 apresenta o IFP para a dimensão renda. Verifica-se índice com valores altos para a maioria dos municípios da Região Nordeste, que pode ser observado pela tonalidade mais escura que predomina na ilustração. Destacam-se os localizados principalmente na região leste/litorânea do Nordeste, abrangendo todo o território dos estados da Paraíba, Alagoas, Sergipe, leste do Rio Grande do Norte e Pernambuco, parte do Ceará, Piauí, Maranhão e Bahia.

A tabela 4 mostra a distribuição dos municípios conforme o intervalo de classe do IFP renda. Quando são analisados os valores dos intervalos de classe, verifica-se que, apesar da divisão em quatro classes, os valores são mais altos do que das outras dimensões apresentadas. A primeira classe, que indica menor propensão à pobreza, concentra o percentual de municípios com índice de até 0,52. Nessa classe, verifica-se que o percentual de municípios pertencentes em cada estado não chega a $2 \%$. Se analisado o intervalo de até 0,72 , tem-se que Piauí é o estado que apresenta maior percentual de municípios com menor propensão à pobreza, 54,9\%.

Os estados com o maior percentual de municípios na classe que indica maior propensão à situação da pobreza, de 0,78 a 0,86, são Sergipe (53\%), Alagoas (39\%), Pernambuco (35\%), Bahia (33\%), Paraíba (32,7\%) e Rio Grande do Norte (28\%). Verifica-se que a maioria dos municípios, mais de 76\%, apresenta índice nas classes que indicam maior propensão a pobreza, acima de 0,73 . 
Figura 4

Índice fuzzy da pobreza para a dimensão renda

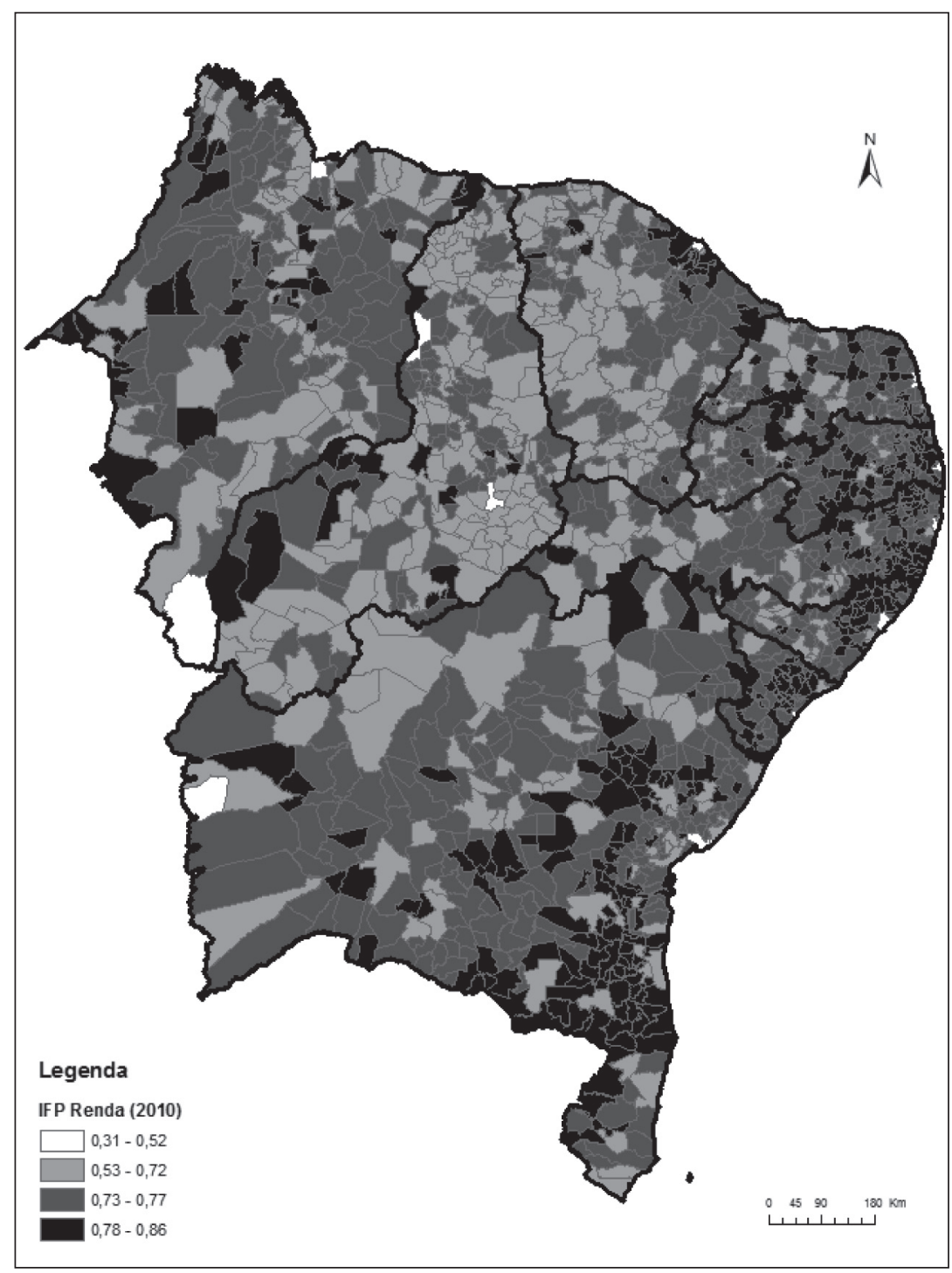

Fonte: Elaborada com dados do IBGE - Censo Demográfico 2010.

Conforme o quadro 2, o indicador que possui maior peso no índice da dimensão se refere ao rendimento médio mensal dos domicílios $(1,8)$. O outro indicador considerado, percentual de domicílios com rendimento de até meio salário mínimo, apresentou peso de 0,79. Essa propensão à pobreza na dimensão renda também foi verificada em Brandolini e D'Alessio (1998) e Carvalho, Kerstenetzky e Del-Vecchio (2007). 
Tabela 4

Municípios por intervalo de classes do IFP renda

\begin{tabular}{|cccccc|}
\hline \multirow{5}{*}{ Estado } & Número de & \multicolumn{4}{c|}{ Percentual de municípios por intervalo de classes (\%) } \\
\cline { 3 - 6 } & municípios & $0,31-0,52$ & $0,53-0,72$ & $0,73-0,77$ & $0,78-0,86$ \\
\hline Alagoas & 102 & 0,98 & 13,73 & 46,08 & 39,22 \\
Bahia & 417 & 0,72 & 15,59 & 50,36 & 33,33 \\
Ceará & 184 & 0,54 & 36,41 & 49,46 & 13,59 \\
Maranhão & 217 & 0,92 & 30,41 & 51,61 & 17,05 \\
Paraíba & 223 & 0,90 & 8,97 & 57,40 & 32,74 \\
Pernambuco & 185 & 1,08 & 18,92 & 44,86 & 35,14 \\
Piauí & 224 & 0,89 & 54,02 & 37,95 & 7,14 \\
Rio Grande do Norte & 167 & 1,20 & 13,77 & 56,89 & 28,14 \\
Sergipe & 75 & 1,33 & 4,00 & 41,33 & 53,33 \\
Total NE & 1794 & 0,89 & 23,08 & 49,16 & 26,87 \\
\hline
\end{tabular}

Fonte: Elaborada com dados do IBGE - Censo Demográfico 2010.

A dimensão renda ainda é a que apresenta maior impacto sobre a pobreza. Para a maior parte dos municípios, o acesso à renda significa a maior privação sofrida pelas pessoas.

\subsection{IFP total}

Com a agregação de todas as dimensões, chega-se ao IFP global. Na figura 5 observa-se maior propensão à situação da pobreza nos municípios das regiões oeste e centro do Nordeste, no Maranhão, Piauí e Alagoas. A menor propensão está no Ceará, Rio Grande do Norte, Pernambuco e sul da Bahia.

A tabela 5 mostra a distribuição dos municípios por intervalo de classe do IFP. Na classe que indica maior propensão à pobreza, acima de 0,68, destacam-se os municípios de Alagoas (57,7\%), Maranhão (54,8\%), Piauí (51\%) e Paraíba (33,6\%). Na classe que indica menor propensão à pobreza, abaixo de 0,47 , os municípios do Rio Grande do Norte $(6,6 \%)$, Bahia (6\%) e Pernambuco (5\%).

Para o total de municípios do Nordeste, tem-se que $23 \%$ se encontram nas classes que indicam menor grau de propensão à pobreza global e $77 \%$ se encontram nas classes que indicam maior grau de propensão à pobreza. Tais resultados demonstram a existência de muitos municípios em situação da pobreza. 
Figura 5

Índice fuzzy da pobreza

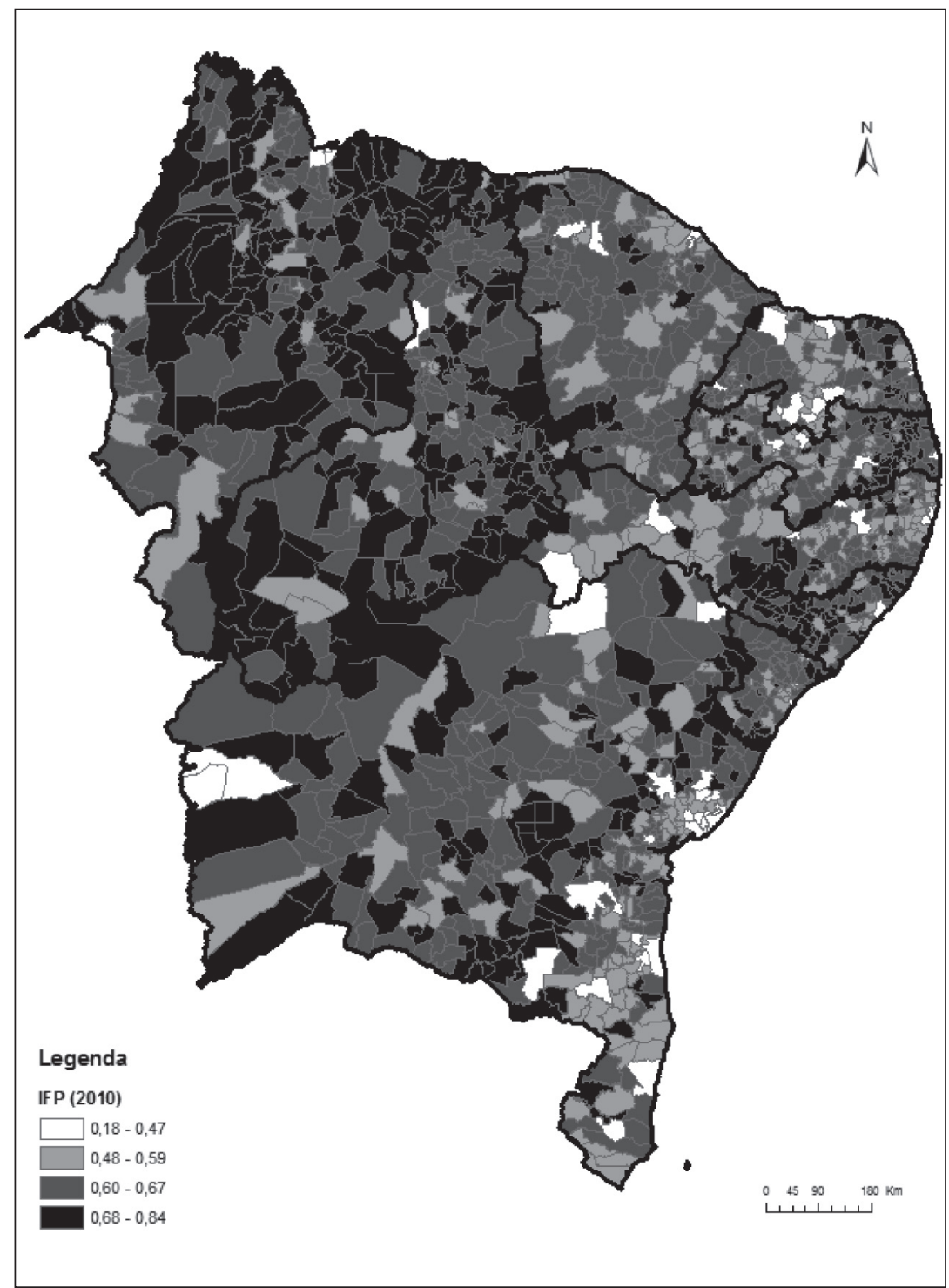

Fonte: Elaborada com dados do IBGE - Censo Demográfico 2010.

Por fim, para mostrar um panorama do IFP para cada estado, elaborou-se um IFP médio estadual a partir da média aritmética simples dos valores dos índices calculados para os municípios. Desse modo, pode-se verificar qual está em situação de maior propensão à pobreza, conforme a tabela 6 . 
Tabela 5

Municípios por intervalo de classes do IFP

\begin{tabular}{|cccccc|}
\hline & \multicolumn{5}{c|}{ IFP } \\
\hline \multirow{2}{*}{ Estado } & Número de & \multicolumn{2}{c|}{ Percentual de municípios por intervalo de classes (\%) } \\
\cline { 3 - 6 } & municípios & $0,18-0,47$ & $0,48-0,59$ & $0,60-0,67$ & $0,68-0,84$ \\
\hline Alagoas & 102 & 0,98 & 11,76 & 29,41 & 57,84 \\
Bahia & 417 & 6,00 & 23,02 & 44,60 & 26,38 \\
Ceará & 184 & 2,17 & 20,11 & 69,02 & 8,70 \\
Maranhão & 217 & 1,84 & 6,91 & 36,41 & 54,84 \\
Paraíba & 223 & 2,24 & 21,52 & 42,60 & 33,63 \\
Pernambuco & 185 & 5,41 & 37,30 & 45,41 & 11,89 \\
Piauí & 224 & 0,45 & 7,59 & 40,63 & 51,34 \\
Rio Grande do Norte & 167 & 6,59 & 24,55 & 50,30 & 18,56 \\
Sergipe & 75 & 4,00 & 21,33 & 56,00 & 18,67 \\
Total NE & 1794 & 3,57 & 19,57 & 45,60 & 31,27 \\
\hline
\end{tabular}

Fonte: Elaborada com dados do IBGE - Censo Demográfico 2010.

Tabela 6

Média do Índice Fuzzy da pobreza para os estados do Nordeste

\begin{tabular}{|c|c|c|c|c|c|}
\hline Estados & $\begin{array}{l}\text { IFP Educação } \\
\text { (ponderado) }\end{array}$ & $\begin{array}{l}\text { IFP Saúde } \\
\text { (ponderado) }\end{array}$ & $\begin{array}{c}\text { IFP Condições } \\
\text { Habitacionais } \\
\text { (ponderado) }\end{array}$ & $\begin{array}{l}\text { IFP Renda } \\
\text { (ponderado) }\end{array}$ & $\begin{array}{c}\text { IFP } \\
\text { (ponderado) }\end{array}$ \\
\hline Alagoas & $* 0,733$ & $* 0,619$ & 0,322 & $* 0,762$ & $* 0,673$ \\
\hline Bahia & 0,617 & 0,554 & 0,298 & $* 0,756$ & 0,620 \\
\hline Ceará & 0,597 & $* 0,605$ & 0,324 & $* 0,736$ & 0,622 \\
\hline Maranhão & 0,646 & $* 0,697$ & $*_{0,475}$ & $* 0,740$ & $* 0,675$ \\
\hline Paraíba & $*^{*} 0,684$ & 0,523 & 0,306 & $* 0,757$ & $* 0,633$ \\
\hline Pernambuco & 0,641 & 0,432 & 0,286 & $* 0,754$ & 0,597 \\
\hline Piauí & $* 0,707$ & $* 0,653$ & $*_{0,418}$ & $* 0,723$ & $* 0,669$ \\
\hline Rio Grande do Norte & 0,624 & 0,561 & 0,209 & $* 0,754$ & 0,614 \\
\hline Sergipe & 0,622 & 0,556 & 0,211 & $* 0,767$ & 0,617 \\
\hline
\end{tabular}

Fonte: Elaborada com os resultados do IFP.

Nota: Os estados com (*) são os que se destacaram com maior grau de propensão à situação da pobreza.

Observa-se que na dimensão educação os estados que apresentaram maior propensão à situação da pobreza foram Alagoas, Piauí e Paraíba. Na dimensão saúde foram Maranhão, Piauí, Alagoas e Ceará. Na dimensão condições habitacionais foram Maranhão e Piauí. Na 
dimensão renda, os valores do índice para todos ficaram bastante aproximados, indicando praticamente a mesma propensão à pobreza. E no índice IFP os que apresentaram maior propensão foram Maranhão, Alagoas, Piauí e Paraíba.

Os resultados encontrados comprovam, para os municípios da Região Nordeste, o que Amartya Sen defende com a abordagem das capacitações. Além disso, se aproximam dos resultados encontrados em outros estudos, como Brandolini e D'Alessio (1998), ChiapperoMartinetti (2000), Picolotto (2006), Carvalho, Kerstenetzky e Del-Vecchio (2007), Pacheco, Del-Vechio e Kerstenetzky (2010) e Diniz e Diniz (2009). Apesar de a dimensão da renda ter apresentado o maior peso, as dimensões de educação e saúde merecem mais atenção devido ao alto grau de propensão à situação da pobreza apresentado pelos municípios. Como destacado por Sen (2000), a renda não é o único fator a ser considerado quando se investiga pobreza. Conforme o autor, é preciso que as pessoas desfrutem de funcionamentos relevantes, por meio do acesso à educação e melhores condições de moradia e saúde, para que tenham uma vida digna, com mais liberdade para, assim, serem agentes das suas vidas.

\section{Considerações finais}

A aplicação da teoria dos conjuntos fuzzy neste estudo permitiu comprovar a tese defendida por Amartya Sen, com a abordagem das capacitações, de que pobreza significa privação em diferentes dimensões relacionadas com a vida das pessoas. Os resultados indicam privação nos municípios da Região Nordeste principalmente nos funcionamentos relacionados com o acesso aos ensinos fundamental, médio e superior, educação do responsável pelo domicílio, aos serviços básicos para uma moradia decente, como acesso à rede de água e esgoto, e acesso ao rendimento mensal.

Tais resultados estão de acordo com estudos que investigam a pobreza por meio da mesma técnica. Chiappero-Martinetti (2000) e Picolotto (2006) concluem em seus estudos que a maior pobreza se encontra na dimensão educação. Neste estudo, fica evidente a propensão à pobreza dos municípios, principalmente nos indicadores relacionados com o acesso ao ensino. Diniz e Diniz (2009) concluem que o indicador que apresenta maior peso no índice de pobreza é o acesso ao esgotamento sanitário, que neste trabalho teve maior peso dentro da dimensão saúde. Com relação à dimensão habitação, os estudos também mostram que indicadores de acesso à rede de água e estrutura domiciliar (energia, banheiro, densidade) impactam na pobreza, como Diniz e Diniz (2009), Carvalho, Kerstenetzky e Del-Vecchio (2007), Pacheco, Del-Vechio e Kerstenetzky (2010). E a dimensão renda, como já era esperado, apresentou o maior impacto, no mesmo sentido de Brandolini e D’Alessio (1998).

Constatou-se que nos estados de Maranhão, Piauí, Alagoas e Paraíba a maioria dos municípios apresenta grande propensão à situação da pobreza no seu aspecto multidimensional. Enquanto nos estados de Pernambuco e Rio Grande do Norte os municípios apresentaram menor propensão à pobreza multidimensional. No Piauí, a maior propensão à pobreza encontra-se na dimensão condições habitacionais, diferentemente dos demais, em que se encontra 
na dimensão renda. Esse resultado em especial denota que a pobreza se deve a diferentes dimensões e pode variar de um local para outro. Existem diferenças entre os municípios que precisam ser observadas quando se estuda pobreza na Região Nordeste. A teoria de Sen mostra que políticas de assistência aos pobres precisam considerar as particularidades de cada local, de forma a verificar quais são as reais privações sofridas pelas pessoas.

A pobreza na Região Nordeste é um problema complexo e tem uma característica multidimensional. Um primeiro passo seria olhar mais atentamente e promover ações de melhoria da educação. O acesso ao ensino básico é fundamental para que as pessoas consigam realizar funcionamentos que consideram importantes para expandir suas capacitações, exercer papel de agente e levar uma vida digna, como defende a abordagem das capacitações.

Ressalta-se que as informações utilizadas neste estudo não formam uma lista rígida a ser seguida, mas apontam uma direção na tentativa de contribuir para a discussão do problema. Os formuladores de políticas precisam conhecer as diferentes necessidades da população de forma que possam propor projetos de melhoria do que é mais urgente. É preciso que políticas de combate à pobreza promovam o acesso a diferentes aspectos relacionados com a vida das pessoas, de forma a permitir uma melhor condição de vida e inserção social.

\section{Referências}

ALKIRE, Sabina. Choosing dimensions: the capability approach and multidimensional poverty. University Library of Munich: Munich Personal RePEc Archive (MPRA Paper n. 8.862), May. 2008.

ALKIRE, Sabina. Dimensions of human development. World Development, v. 30, n. 2, p. 181-205, 2002.

BAGOLIN, Izete P.; ÁVILA, Rodrigo P. Poverty distribution among the Brazilian states: a multidimensional analysis using capabilities and need approaches. In: ENCONTRO NACIONAL DE ECONOMIA (ANPEC), 34., 2006, Recife. Anais eletrônicos... Salvador: Anpec, 2006. Disponível em: <www. anpec.org.br/encontro2006/artigos/A06A142.pdf>. Acesso em: 27 mar. 2012.

BALIAMOUNE-LUTZ, Mina. On the measurement of human well-being: fuzzy set theory and Sen's capability approach. Tóquio: United Nations University: World Institute of Development Research, 2004. (WIDER, Research Paper n. 2.004/16).

BRANDOLINI, Andrea; D'ALESSIO, Giovanni. Measuring well-being in the functioning space. Roma: Banca d'Italia, 1998.

BRASIL. Presidência da República. Decreto nº 7.492 de 2 de junho de 2011. Institui o Plano Brasil Sem Miséria. Brasília, 2 jun. 2011a. Disponível em: <www.planalto.gov.br>. Acesso em: 27 mar. 2012.

BRASIL. Ministério do Desenvolvimento Social e Combate à Fome. Nota MDS: o perfil da extrema pobreza no Brasil com base nos dados preliminares do universo do Censo 2010. Brasília, 2 maio 2011b. Disponível em: <www.brasilsemmiseria.gov.br>. Acesso em: 27 mar. 2012. 
CARVALHO, Maristela; KERSTENETZKY, Célia L.; DEL VECCHIO, Renata. Uma aplicação da teoria dos conjuntos fuzzy na pobreza: o caso das Regiões Metropolitanas do Sudeste brasileiro - 2000. In: ENCONTRO NACIONAL DE ECONOMIA (ANPEC), 35. 2007, Recife. Anais eletrônicos... Recife: Anpec, 2007. Disponível em: <www.anpec.org.br/encontro2007/artigos/A07A001.pdf>. Acesso em: 27 mar. 2012.

CHIAPPERO-MARTINETTI, Enrica. A multidimensional assessment of well-being based on sen's functioning approach. Rivista Internazionale di Scienze Sociali, n. 2, p. 207-239, 2000.

COMIM, Flavio. Operationalizing sen's capability approach. In: CONFERENCE JUSTICE AND POVERTY: EXAMINING SEN'S CAPABILITY APPROACH, 2001, Cambridge, Inglaterra. Anais eletrônicos... Disponível em: <www.st-edmunds.cam.ac.uk/vhi/> . Acesso em: 27 mar. 2012.

DINIZ, Marcelo B.; DINIZ, Marcos M. Um indicador comparativo de pobreza multidimensional a partir dos objetivos do desenvolvimento do milênio. Economia Aplicada, v. 13, n. 3, p. 399-423, 2009.

INSTITUTO BRASILEIRO DE GEOGRAFIA E ESTATÍSTICA (IBGE). Censo Demográfico 2010. Disponível em: <www.sidra.ibge.gov.br>. Acesso em: 27 jan. 2012.

LELLI, Sara. Factor analisys vs. fuzzy sets theory: assessing the influence of different techniques on Sen's functioning approach. Center for Economic Studies, K. U. Leuven, 2001.

MARIN, Solange R. et al. Pobreza multidimensional em Silveira Martins-RS: identificação de dimensões de vida valoradas com a aplicação do método Alkire-Foster (AF). Cadernos de Gestão Pública e Cidadania, São Paulo, v. 19, n. 62, p. 60-77, jan./jun. 2013.

MARIN, Solange R.; OTTONELLI, Janaina. Medida multidimensional de pobreza: um exercício em Palmeira das Missões-RS. Redes (Santa Cruz do Sul), v. 13, n. 3, p. 241-265, set./dez. 2008.

OTTONELLI, Janaina et al. A importância das medidas multidimensionais de pobreza para a administração pública: um exercício em Palmeira das Missões (RS). Rev. Adm. Pública, v. 45, n. 3, p. 837-859, maio/jun. 2011.

PACHECO, Kleber; DEL-VECCHIO, Renata; KERSTENETZKY, Célia L. Pobreza fuzzy multidimensional: uma análise das condições de vida na Zona Oeste do Rio de Janeiro 1991 a 2000. Niterói, RJ: Centro de Estudos sobre Desigualdade e Desenvolvimento, 2010. (Cede, Texto para discussão n. 30).

PICOLOTTO, Volnei C. Pobreza e desenvolvimento sob os paradigmas da renda e das capacitações: uma aplicação para a Grande Porto Alegre através de indicadores fuzzy. Dissertação (mestrado em economia) - Universidade Federal do Rio Grande do Sul, Porto Alegre, 2006.

PROGRAMA DAS NAÇÕES UNIDAS PARA O DESENVOLVIMENTO (Pnud). Human development report 2010 (20th anniversary edition): the real wealth of nations: pathways to development human. Nova York: Palgrave Macmillan, 2010.

PROGRAMA DAS NAÇÕES UNIDAS PARA O DESENVOLVIMENTO (Pnud). Human development report 2011: sustainability and equity: a better future for all. Nova York: Palgrave Macmillan, 2011.

SEN, Amartya K. Desenvolvimento como liberdade. São Paulo: Companhia das Letras, 2000. 
SEN, Amartya K. Desigualdade reexaminada. Rio de Janeiro: Record, 2001.

SEN, Amartya K. Poverty and famines: an essay on entitlement and deprivation. Oxford: Oxford University Press, 1981.

SEN, Amartya K. Sobre ética e economia. São Paulo: Companhia das Letras, 1999.

SEN, Amartya K. Well-being, agency and freedom: the Dewey lectures, 1984. The Journal of Philosophy, v. 82, n. 4, p. 169-221, abr. 1985.

ZADEH, Lotfi A. Fuzzy sets. Information and Control, v. 8, p. 338-353, 1965.

Janaina Ottonelli é doutoranda em administração pela Universidade Federal de Santa Maria (PPGA/ UFSM) e mestre em economia pelo Programa de Pós-Graduação em Economia da Universidade Federal do Rio Grande do Norte (PPGECO/UFRN).E-mail: janainaottonelli@gmail.com.

Jorge Luiz Mariano é doutor em economia e professor do Programa de Pós-Graduação em Economia da Universidade Federal do Rio Grande do Norte (PPGECO/UFRN). E-mail: jdal@ufrnet.br. 
